\title{
PESQUISA EM SAÚDE E RESPONSABILIDADE SOCIAL
}

\section{Sônia Maria Soares ${ }^{1}$}

Em tempos de incerteza, chegamos ao final de 2018 celebrando conquistas e realizações, mas com muitas inquietações e dúvidas frente às reformas sociais e econômicas, que podem surgir a partir do atual cenário político brasileiro. Portanto, colocar à disposição dos leitores da REAS mais um número da revista, é acima de tudo, uma conquista e a garantia do cumprimento da sua missão de difundir a ciência da enfermagem e áreas afins. Ao mesmo tempo, cabe aplaudir a aprovação da indexação da REAS na base de dados CINAHL- Cumulative Index to Nursing and Allied Health Literature, o que amplia a divulgação e a exposição do periódico.

Escrever o editorial da REAS, neste momento, foi, portanto, um desafio instigante e em tom de muita reflexão, ousei pontuar algumas questões sobre a pesquisa em saúde e a responsabilidade social na produção do conhecimento.

A motivação para trazer esta temática nesse editorial partiu inicialmente de um artigo que tive oportunidade de revisitar recentemente intitulado: Desafios da pesquisa no Brasil: uma contribuição ao debate (UNICAMP, 2002). O artigo demonstra-se muito atual ao discutir a responsabilidade social das instituições de pesquisa do país, em particular das mantidas com verbas públicas, considerando o debate para apontar falhas e limitações do sistema na produção do conhecimento científico frente à escassez de recursos financeiros.

É indiscutível o avanço dos indicadores da produção científica brasileira que aumentou 125\% na última década (AJE, 2016). Apesar dos dados apresentados demonstrarem os resultados dos investimentos realizados no passado, é fundamental nesse momento de contingenciamento de verbas refletirmos criticamente sobre qual é a ciência e a tecnologia que o país precisa para superar suas dificuldades e aproximar-se dos países desenvolvidos (UNICAMP, 2002). Muito tem sido comentado na atualidade sobre os cortes de recursos financeiros, que estão afetando e podem se agravar de forma drástica a produção da pesquisa no âmbito das universidades públicas federais, onde se concentra grande parte da investigação científica produzida no país. Segundo dados da ANDIFES (2018) o repasse total garantido pelo MEC encolheu 28,5\% nos últimos cinco anos. Dois fatores cooperaram para aumentar a dificuldade financeira enfrentada pelo setor científico: a Emenda Constitucional 95, que

\footnotetext{
${ }^{1}$ Enfermeira, doutora em Saúde Pública, atual Diretora da Escola de Enfermagem da Universidade Federal de Minas Gerais, coordenadora do Núcleo de Estudos e Pesquisas em Cuidado e Desenvolvimento Humano/ CNPq.
} 
congelou investimentos financeiros pelos próximos anos, e a utilização de recursos do Fundo Nacional de Desenvolvimento Científico e Tecnológico para pagamento de dívida pública.

Assim, é preciso reconhecer a necessidade cada vez maior de desenvolver parcerias que prosperem com forças compartilhadas e ações intersetoriais. Trata-se de dimensionar quais são os temas estratégicos para subsidiar políticas públicas, garantir o atendimento das demandas sociais, a qualidade dos serviços de saúde e impulsionar transformação e mudanças na formação profissional e na prática assistencial. Neste sentido, acredito que antes de iniciar qualquer projeto é essencial refletir se de fato trata-se de pesquisa socialmente responsável e de que modo os resultados poderão produzir impacto nos cenários de prática contribuindo para o desenvolvimento científico, tecnológico, social e cultural.

Este número da REAS apresenta os resultados de pesquisas que demonstram compromisso com a qualidade do cuidado de enfermagem em diferentes cenários, e que contribuem para o aprimoramento das práticas no Sistema Único de Saúde (SUS) e demais instituições.

Não se trata de buscar respostas imediatas, mas sim, de abrir espaços para refletir, discutir e construir novos projetos! Agradeço a oportunidade de contribuir com o crescimento da REAS!

Com muita inspiração desejo boa leitura a todos!

\section{REFERÊNCIAS}

1. Associação Nacional dos Dirigentes das Instituições Federais de Ensino Superior: Repasses do MEC para universidades federais chegam ao menor patamar em sete anos Disponível em: http://www.andifes.org.br/repasses-mec-para-universidades-federais acesso em 24/11/2018.

2. Instituto Nacional de Estudos e Pesquisas Educacionais Anísio Teixeira: Sinopse Estatística da Educação Superior 2017: Brasília, INEP, 2018. Disponível em http://portal.inep.gov.br/sinopse-sinopse acesso em 04/01/2018

3. Financiadora de Estudos e Projetos- FINEPhttp://www.finep.gov.brwww.finep.gov.br/images/afinep/Politica/16_03_2018_Estrategia_Nacional_de_Ciencia_Tecnologia_e_Inovacao_2016_ 2022.pdf acesso em 28/12/2018

4. American Journal Experts (AJE) Relatório AJE de Publicações Acadêmicas: Brasil. American Journal Experts (AJE) [Internet]. 2016. 2 p. Disponível em: https://www.aje.com/br/arc/dist/docs/Brazil-scholarly-publishing-report-2016-translated.pdf 5. Desafios da pesquisa no Brasil: uma contribuição ao debate. São Paulo Perspec., São Paulo, v. 16, n. 4, p. 15-23, Oct. 2002. Availablehttp://www.scielo.br/scielo.php?script=sci_arttext\&pid=S0102$88392002000400004 \& \operatorname{lng}=$ en $\& n r m=i s o>$. access on 02 Jan. 2019. http://dx.doi.org/10.1590/S0102-8839200200040000 